\title{
Adherence to the neonatal resuscitation algorithm for preterm infants in a tertiary hospital in Spain
}

Silvia Maya-Enero ${ }^{1^{*}} \mathbb{D}$, Francesc Botet-Mussons ${ }^{1}$, Josep Figueras-Aloy ${ }^{1}$, Montserrat Izquierdo-Renau², Marta Thió ${ }^{2}$ and Martin Iriondo-Sanz ${ }^{2}$

\begin{abstract}
Background: There is evidence that delivery room resuscitation of very preterm infants often deviates from internationally recommended guidelines. There were no published data in Spain regarding the quality of neonatal resuscitation. Therefore, we decided to evaluate resuscitation team adherence to neonatal resuscitation guidelines after birth in very preterm infants.

Methods: We conducted an observational study. We video recorded resuscitations of preterm infants $<32$ weeks' gestational age and evaluated every step during resuscitation according to a score-sheet specifically designed for this purpose, following Carbine's method, where higher scores indicated that more intense resuscitation maneuvers were required. We divided the score achieved by the total possible points per patient to obtain the percentage of adherence to the algorithm. We also compared resuscitations performed by staff neonatologists to those performed by pediatricians on-call. We compared percentages of adherence to the algorithm with the Chi-square test for large groups and Fisher's exact test for smaller groups. We compared assigned Apgar scores with those given after analyzing the recordings and described them by their median and interquartile range. We measured the interrater agreement between Apgar scores with Cohen's kappa coefficient. Linear and logarithmic regressions were drawn to characterize the pattern of algorithm adherence. Statistical analysis was performed using SPSS V.20. A p-value $<0.05$ was considered significant. Our Hospital Ethics Committee approved this project, and we obtained parental written consent beforehand.
\end{abstract}

Results: Sixteen percent of our resuscitations followed the algorithm. The number of mistakes per resuscitation was low. Global adherence to the algorithm was $80.9 \%$. Ventilation and surfactant administration were performed best, whereas preparation and initial steps were done with worse adherence to the algorithm. Intubation required, on average, 2.2 attempts; success on the first attempt happened in 33.3\% of cases. Only 12.5\% of intubations were achieved within the allotted $30 \mathrm{~s}$. Many errors were attributable to timing. Resuscitations led by pediatricians on-call were performed as correctly as those by staff neonatologists.

Conclusions: Resuscitation often deviates from the internationally recognized algorithm. Perfectly performed resuscitations are infrequent, although global adherence to the algorithm is high. Neonatologists and pediatricians need intubation training.

Keywords: Neonatal resuscitation, Video recording, Very preterm infant, Delivery room

\footnotetext{
* Correspondence: smaya1@clinic.cat

${ }^{1}$ Neonatology Service, Hospital Clínic, seu Maternitat, ICGON (Institut Clínic

de Ginecologia, Obstetrícia i Neonatologia), Barcelona University, Sabino de

Arana, 1, 08028 Barcelona, Spain

Full list of author information is available at the end of the article
}

(c) The Author(s). 2018 Open Access This article is distributed under the terms of the Creative Commons Attribution 4.0 International License (http://creativecommons.org/licenses/by/4.0/), which permits unrestricted use, distribution, and reproduction in any medium, provided you give appropriate credit to the original author(s) and the source, provide a link to the Creative Commons license, and indicate if changes were made. The Creative Commons Public Domain Dedication waiver (http://creativecommons.org/publicdomain/zero/1.0/) applies to the data made available in this article, unless otherwise stated. 


\section{Background}

Neonatal resuscitation (NR) is the most frequently performed resuscitation in hospitals [1-3]. Infants that are more immature are more likely to require support. Approximately $85 \%$ of very preterm neonates need intervention during transition after birth and their viability and prognosis greatly depend on the care they receive in the delivery room (DR) [4-6]. Most preterm infants initiate breathing after birth, but they often have a weak, insufficient respiratory drive. Guidelines recommend tactile stimulation (warming, drying and rubbing the back or soles of the feet) to stimulate breathing. Guidelines exist to standardize and optimize resuscitation. However, there is evidence that the sequence and quality of interventions during NR often deviate from guidelines [3, 7-11]. Video recording has been widely used for educational and clinical quality assessment purposes, with good acceptance by caregivers $[12,13]$. It is inexpensive, it does not interfere with resuscitation, and it offers data to assess performance accurately. Video reviewing reinforces teamwork and permits identification and amendment of errors that otherwise could be neglected. Combining the recording of physiological parameters (ECG, pulse oximetry (PO), capnography and respiratory function monitoring) with video images helps audit performance [12-15]. There is a lack of information about adherence to NR guidelines in Spain. Consequently, we sought to evaluate adherence to NR guidelines in very preterm neonates at our hospital. Our main hypothesis was that resuscitation often deviates from the algorithm. A secondary hypothesis was that staff neonatologists perform better than pediatricians on-call because they work only with neonates and have more experience on average, whereas pediatricians are younger and work with children up to 18 years.

\section{Methods}

We conducted this observational study at Hospital Clínic de Barcelona, a tertiary referral center in Spain where approximately 150 babies < 32 weeks' gestational age (GA) are born every year. Our Hospital Ethics Committee approved this project. We recorded and analyzed these infants' resuscitations after obtaining written parental informed consent. We aimed to analyze as many NRs as possible. However, given the difficulties in obtaining parental consent in such moments of stress, we aimed to analyze a representative sample of at least one-third of all NRs performed. Thus, we decided to record 50 resuscitations. We had planned to obtain the data in 1 year, although it took us longer (16 months), as fewer candidates were born during the study period than expected. This study was the basis for the doctoral thesis of the main author (see link in http://www.ub.edu/medicina/doctorat/lectura.htm May 27, 2011). However, the data were never published. The authors believe that the results and conclusions may be perfectly applicable today.

Inclusion criteria: All babies $<32$ weeks GA were candidates for inclusion in this study. When the pediatrician was required in the delivery room, parents were approached for consent to record the NR. After obtaining written consent, the resuscitator began recording the $\mathrm{NR}$, and that case was included in the study.

All infants were resuscitated under a radiant heater equipped with a neonatal automatic ventilator (Babylog 2, Dräger Medical, Drägerwerk AG \& Co. KGaA, Lübeck, Germany) that included an oxygen blender and could provide Continuous Positive Airway Pressure (CPAP) and Positive Pressure Ventilation (PPV) and with a pulse-oximeter (Nellcor ${ }^{\text {Ts }}$ NPB-295, Minneapolis, MN, USA). A Sony Handycam DCR-SR 32 E (Sony, Tokyo, Japan) digital video camera attached to the upper left side of the radiant warmer recorded the newborn, the hands of the resuscitators and the PO screen. The clinical team turned the recording on before the baby was born.

We designed an evaluation sheet to score 12 domains in each resuscitation (Table 1) according to the algorithm of the Spanish Society of Neonatology, adapted from the ILCOR 2005 guidelines (see Fig. 1). We assigned a numerical score to every resuscitation, following Carbine's previously described method [16]: we awarded 2 points for every correct decision and proper procedure, 1 point for delayed interventions or inadequate technique, and 0 points for indicated procedures that were omitted or for inappropriate procedures (for details of how we scored each domain, see Table 1). The total score per resuscitation ("resuscitation score") ranged from 4 to 22 points. A higher score indicated that more intense resuscitation was required. We obtained the percentage of adherence to the algorithm by dividing the score achieved $(\mathrm{X})$ by the maximum possible score per patient that is, $\mathrm{X}$ of a potential of (4-22) points, as a percentage. We registered admission temperature and Apgar scores at 1, 5 and 10 minutes ( $\mathrm{min})$ as assigned by the caregiver and after video recording review.

We compared two groups of resuscitators: staff neonatologists (group N) and pediatricians on-call (group P). Neonatologists on-call performed a few of the resuscitations after-hours.

\section{Statistic analysis}

We present the characteristics of our study population and its subgroups using the median, standard deviation (SD) and range for quantitative variables (gestational age, birth weight, temperature at admission and adherence to the algorithm and resuscitation score). We 
Table 1 Data collection sheet

\begin{tabular}{|c|c|}
\hline Patient's identification: & \\
\hline Birth weight: & \\
\hline Twin? 1st or 2 nd of 2 & \\
\hline C-section? & \\
\hline Apgar score: assigned: 1 min: & 5 min: 10 min: \\
\hline Apgar score: camera: 1 min: & 5 min: 10 min: \\
\hline Admission temperature: ${ }^{\circ} \mathrm{C}$ & \\
\hline Analyzed aspects & 0 points \\
\hline $\begin{array}{l}\text { Heat loss prevention } \\
\text { measures }^{\mathrm{a}}\end{array}$ & Not performed \\
\hline $\begin{array}{l}\text { Head in a "sniffing } \\
\text { position"a }\end{array}$ & Not performed \\
\hline Suctioning & Not performed when indicated \\
\hline Stimulation & $\begin{array}{l}\text { Not performed when indicated: } \\
\text { inactive, apneic or not } \\
\text { spontaneously breathing, or gasping, } \\
\text { or bradycardic }\end{array}$ \\
\hline Preductal PO probe & $\begin{array}{l}\text { Not placed in a baby who needed } \\
\text { CPAP, PPV or oxygen }\end{array}$ \\
\hline $\begin{array}{l}\text { Administration of } \\
\text { oxygen }\end{array}$ & Not used in a baby who needed it \\
\hline $\begin{array}{l}\text { Administration of } \\
\text { CPAP }\end{array}$ & $\begin{array}{l}\text { Mandatory if }<28 \text { weeks GA or } \geq 29 \\
\text { with a positive initial evaluation but } \\
\text { distress }\end{array}$ \\
\hline $\begin{array}{l}\text { Administration of } \\
\text { mask PPV }\end{array}$ & Not performed when needed \\
\hline
\end{tabular}

Intubation Not performed when needed

Chest compressions Not performed when needed

\section{Gestational age:}

Sex:

Time and date of birth
1 point (any technical error in a correctly indicated maneuver is awarded 1 point; the main errors and examples are listed in every domain)

No cap; baby dried with towels and then placed in a plastic wrap; if towels were used, they had to be replaced by new, preheated ones

Head in hyperextension or bent or to a side

Done after the first $20 \mathrm{~s}$; for more than $5 \mathrm{~s}$; incorrect order (nasal suction before oral); incorrect suction catheter (not 8 F); excessively introduced catheter (more than $10 \mathrm{~cm}$ )

Stimulation performed on other places than the back or the soles of the feet Too aggressive (not gentle rubbing)

Not preductal (left hand or wrist, foot)

Given free-flow oxygen; not administered with PPC or PPV; not discontinued when color or $\mathrm{SpO}_{2}$ improved; use of initial $\mathrm{FiO}_{2}$ other than 0.3

Evident mask leak; incorrect mask/cannula size

Initiation after the first $20 \mathrm{~s}$; use of a self-inflating bag instead of an automatic or manual ventilator; incorrect mask size; incorrect rate (not 40-60 rpm); mask leak; not re-evaluated for response (HR and color) after $30 \mathrm{~s}$ )

Duration of each intubation attempt (time from the introduction of the laryngoscope blade to the mouth to its removal) $>30 \mathrm{~s}$ ); incorrect size of the endotracheal tube: position of the endotracheal tube not checked (auscultation/chest wall rise/inserted to correct depth); lack of ventilation between intubation attempts, Number of intubation attempts; Unplanned extubation

Incorrect method (other than 2 thumbs or 2 fingers); incorrect area (other than lower third of the sternum); incorrect depth (not one third of the anterior-posterior diameter of the chest); incorrect rate (not $90 \mathrm{bpm}$ ); incorrect coordination with ventilation (not 3:1): initiation without correct ventilation; Not re-evaluated for response

Not administered after $30 \mathrm{~s}$ of CC if heart rate $<60$ bpm; Dose and route of administration

Not administered at 10 min of life; Dose
2 points

Well done (dried and towels replaced OR plastic wrap)

Well done

Well done

Well done

Preductal (right hand or wrist)

Well done

Well done

Well done

Well done

Well done

Well done

Well done
Not performed when indicated: intubated and $<28$ or $\geq 29$ weeks $\mathrm{GA}$ and $\mathrm{FiO}_{2} \geq 0.3$

Total points 


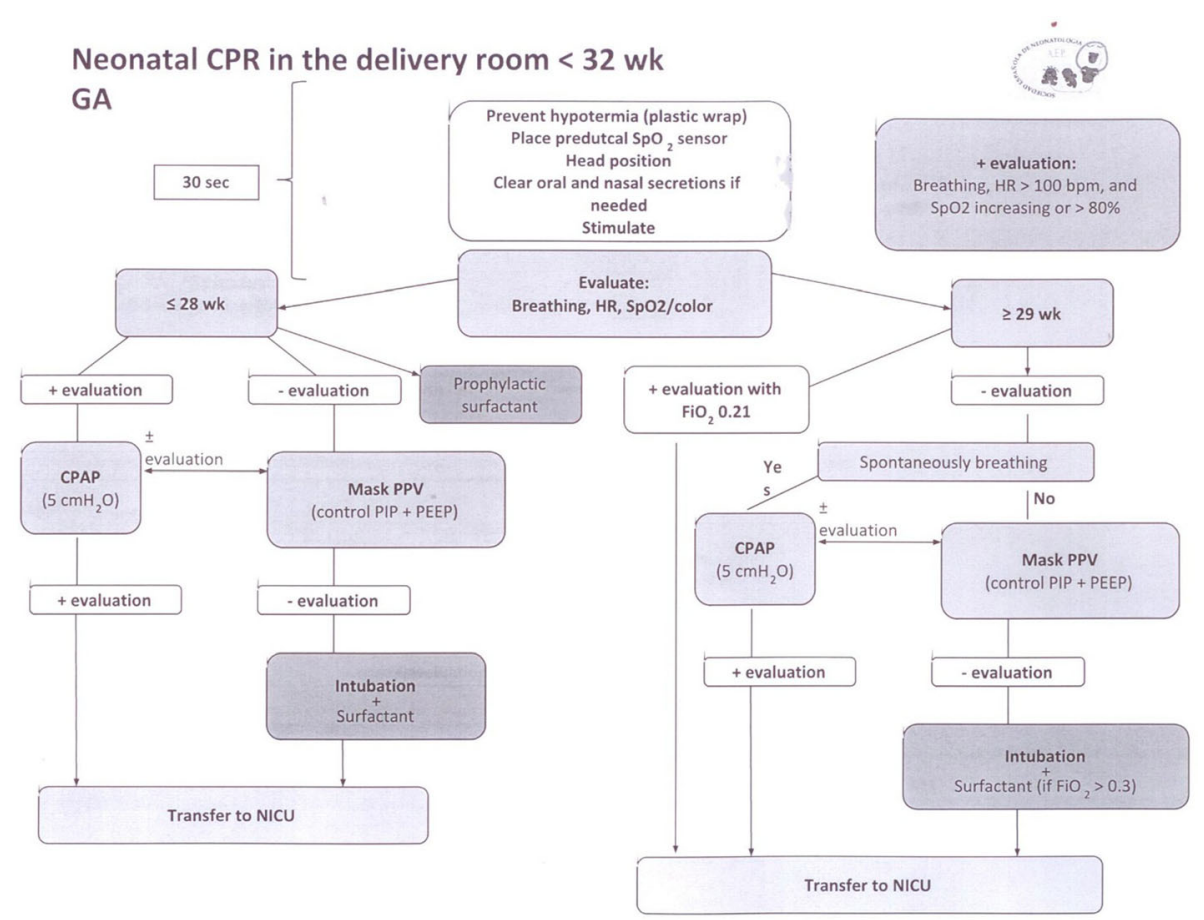

Fig. 1 Algorithm of the Spanish Society of Neonatology for the resuscitation of the very preterm infant. Spanish Society of Neonatology, 2007. Obtained from http://www.se-neonatal.es/Comisionesygruposdetrabajos/GrupodeRCPNeonatal/tabid/76/Default.aspx\#Publicaciones

confirmed homogeneity of our subgroups in terms of gestational age, birth weight and resuscitation score. We used the Shapiro-Wilk test to evaluate normality in our subgroups. We compared normally distributed quantitative variables with a paired T-test between our two groups. For nonnormally distributed quantitative variables, we used the Mann-Whitney U test to compare the two groups.

We compared percentages of adherence to the algorithm for every domain with the Chi-square test for large groups and with Fisher's exact test for smaller groups (fewer than 5 cases). Linear and logarithmic regressions were drawn to characterize the pattern of adherence to the algorithm.

We compared assigned Apgar scores with those given after analyzing the recordings and described them by their median and interquartile range (IQR). We measured interrater agreement between Apgar scores with Cohen's kappa coefficient.

Statistical analysis was performed using SPSS (SPSS for Windows, V.20, Chicago, Illinois, USA). A $p$-value < 0.05 was considered significant.

\section{Results}

Between April 2008 and August 2009, 162 infants < 32 weeks GA were born in our center. We analyzed 50 resuscitations (30.6\%), a representative sample of the population. Groups N (staff neonatologists) and P (pediatricians on-call) were homogeneous. Tables 2 and 3 show the characteristics of our population and subgroups.

Global adherence to the algorithm was $80.9 \pm 14.2 \%$, with no differences between groups $\mathrm{N}$ and $\mathrm{P}(81.5 \pm$ $12.7 \%$ in group $\mathrm{N}$ versus $80.7 \pm 15.0 \%$ in group $\mathrm{P}, P=$ 0.93, Mann-Whitney U), and was independent of the

Table 2 Characteristics of our population and neonates $<32$ weeks GA born during the study period

\begin{tabular}{llll}
\hline Characteristic & Study patients $(n=50)$ & Neonates $<32$ weeks GA born during the study period $(n=162)$ & $P^{c}$ \\
\hline Gestational age, SD (weeks) (range) & $29^{4} \pm 2^{5}\left(25^{5}-31^{6}\right)$ & $29^{1} \pm 2\left(24^{1}-31^{6}\right)$ & ${\text { NS }(0.24)^{\mathrm{a}}}^{\mathrm{a}}$ \\
Male (\%) & $26 / 50(52 \%)$ & $88 / 162(54.3 \%)$ & NS $(0.07)^{\mathrm{b}}$ \\
BW, SD $(\mathrm{g})$ (range) & $1181 \pm 368(460-2015)$ & $1201 \pm 377(340-2475)$ & NS $(0.75)^{\mathrm{a}}$ \\
Twins (\%) & $19 / 50(38)$ & $81 / 162(50)$ & NS $(0.13)^{\mathrm{b}}$ \\
BW $<1500 \mathrm{~g}(\%)$ & $42 / 50(84)$ & $131 / 162(80.8)$ & NS $(0.61)^{\mathrm{b}}$ \\
C-section (\%) & $33 / 50(66)$ & $94 / 162(58)$ & NS $(0.31)^{\mathrm{b}}$ \\
\hline
\end{tabular}

SD Standard Deviation, BW Birth Weight, GA Gestational Age. ${ }^{a}$ Paired T- test, ${ }^{\text {b }}$ Chi-square, ${ }^{c}$ Indicates significance at the $P<0.05$ level. NS: non-significant 
Table 3 Subgroups in our study

\begin{tabular}{llll}
\hline Characteristic & Group N (staff neonatologists) $(n=18)$ & Group P (pediatricians oncall) $(n=32)$ & $P^{d}$ \\
\hline GA (weeks, SD) (range) & $29^{4} \pm 1^{6}\left(25^{5}-31^{6}\right)$ & $29^{3} \pm 1^{4}\left(26^{0}-31^{6}\right)$ & NS $(0.90)^{\mathrm{a}}$ \\
Male (\%) & $8 / 18(44.4)$ & $18 / 32(56.2)$ & NS $(0.61)^{\mathrm{b}}$ \\
BW (g, SD) (range) & $1091 \pm 418(460-1900)$ & $1232 \pm 333(720-2015)$ & NS $(0.20)^{\mathrm{a}}$ \\
RS (possible points) (range) & $12.66 \pm 4.39(6-20)$ & $13.96 \pm 3.71(6-20)$ & NS $(0.29)^{\mathrm{c}}$ \\
\hline
\end{tabular}

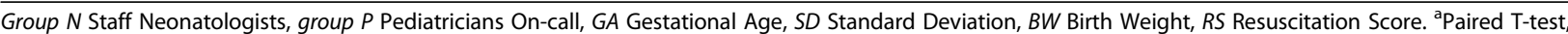

${ }^{\mathrm{b}} \mathrm{Chi}$-square, ${ }^{\mathrm{c}}$ Mann-Whitney $\mathrm{U}$ test, ${ }^{\mathrm{d}}$ Indicates significance at the $P<0.05$ level. NS: non-significant

number of interventions required. Eight resuscitations (16\%) were technically correct; $15 / 50$ (30\%) failed in one domain; $12 / 50$ (24\%) in two; $5 / 50$ (10\%) in three; 6/50 $(12 \%)$ in four; $2 / 50$ (4\%) in five; and $2 / 50$ (4\%) in seven. The mean (SD) resuscitation score was 13.5 (3.9) points/ resuscitation (range: 6-20). Table 4 analyzes the adherence to the algorithm by domains.

Table 5 shows results from measures to prevent heat loss and its relation to admission temperature. We found no differences between the group that received correct measures to prevent hypothermia and the group that did not. Intubation differentiated intensive (16-20 total possible points) from mild resuscitation (6-16 points). Infants who did not need intubation $(n=36)$ had a mean global adherence to the algorithm of $83 \%$. Deviations from the algorithm in this group did not correlate with the intensity of resuscitation $\left(R^{2}=0.0013\right)$.

\section{Some errors we observed \\ Heat loss prevention}

Twelve percent of patients were placed in plastic wrap after drying. When only dried, the technique was correct in $58.1 \%(18 / 31)$ of cases; $22.6 \%(7 / 31)$ did not have the towels changed, and $19.3 \%(6 / 31)$ had no cap. Only $22.4 \%$ of patients $(11 / 49)$ were normothermic (36.5$\left.37.5{ }^{\circ} \mathrm{C}\right)$; $73.5 \%(36 / 49)$ were hypothermic. More critically ill patients were more likely to receive worse anti-hypothermia measures because they were being subjected to other procedures: ventilation, intubation, chest compressions (CC) and surfactant administration. Sixty-eight percent of patients (13/19) in whom heat loss prevention was incorrect had a resuscitation score $\geq 14$ points, which means that they received at least ventilatory support.

\section{Clearing the airway with a suction catheter}

The following errors were observed: oral without nasal suctioning, 16.7\%; undue suction (over $5 \mathrm{~s}$, range $31-50 \mathrm{~s}), 8.3 \%$; use of a larger catheter than recommended, 8.3\%; delayed suctioning after $20 \mathrm{~s}$, $6.2 \%$, or after ventilation, $4.2 \%$; incorrect suctioning order (first nasal), 2.1\%; and excessive introduction of the catheter, $2.1 \%$. We observed no episodes of severe bradycardia during suctioning.

Table 4 Adherence to the algorithm

\begin{tabular}{|c|c|c|c|c|c|c|}
\hline \multirow[t]{2}{*}{ Domain } & \multirow[t]{2}{*}{$\begin{array}{l}\text { Indicated } \\
(\%)\end{array}$} & \multirow[t]{2}{*}{$\begin{array}{l}\text { Performed } \\
\text { (\%) }\end{array}$} & \multicolumn{4}{|c|}{ Adherence to the algorithm (\%) (PO/TTPx100) } \\
\hline & & & Global & Group N & Group P & $p^{3}$ \\
\hline Heat loss prevention & $100(50 / 50)$ & $100(50 / 50)$ & $62(31 / 50)$ & $66.7(12 / 18)$ & $59.4(19 / 32)$ & NS $(0.84)^{2}$ \\
\hline Head in a "sniffing" position & $100(50 / 50)$ & $94(47 / 50)$ & $94(47 / 50)$ & $94.4(17 / 18)$ & $93.7(30 / 32)$ & NS $(0.71)^{1}$ \\
\hline Clearing the airway & $96(48 / 50)$ & $96(48 / 50)$ & $62.5(30 / 48)$ & $55.6(10 / 18)$ & $66.7(20 / 30)$ & NS $(0.59)^{2}$ \\
\hline Stimulation & $64(32 / 50)$ & $30(15 / 50)$ & $93.3^{4}(14 / 15)$ & $80(4 / 5)$ & $100(10 / 10)$ & NS $(0.33)^{1}$ \\
\hline Placing a preductal pulse-oximeter probe & $82(41 / 50)$ & $90.2(37 / 41)$ & $63.4(26 / 41)$ & $76.9(10 / 13)$ & $57.1(16 / 28)$ & NS $(1.49)^{1}$ \\
\hline Administration of oxygen & $68(34 / 50)$ & $68(34 / 50)$ & $94.1(32 / 34)$ & $100(10 / 10)$ & $91.3(21 / 23)$ & NS $(0.48)^{1}$ \\
\hline CPAP & 60 & 60 & 100 & 100 & 100 & - \\
\hline Administration of PPV & $60(30 / 50)$ & $96.7(29 / 30)$ & $79.3(23 / 29)$ & $60(6 / 10)$ & $85(17 / 20)$ & NS $(0.14)^{1}$ \\
\hline Intubation & $32(16 / 50)$ & $87.5(14 / 16)$ & $0(0 / 16)$ & $0(0 / 5)$ & $0(0 / 11)$ & - \\
\hline CC & $4(2 / 50)$ & $2(1 / 50)$ & 0 & 0 & 0 & - \\
\hline Epinephrine administration & $?$ & $4(2 / 50)$ & 0 & 0 & 0 & - \\
\hline Surfactant administration & $24(12 / 50)$ & $20(10 / 50)$ & $\begin{array}{l}100^{4}(10 / 10) \\
83.3 \\
(10 / 12)^{5}\end{array}$ & $75(3 / 4)$ & $87.5(7 / 8)$ & NS $(0.58)^{1}$ \\
\hline
\end{tabular}


Table 5 Heat loss prevention

\begin{tabular}{|c|c|c|c|c|}
\hline Group & Heat loss prevention adherence to algorithm (\%) (PO/TPP) & $P^{c}$ & Admission temperature $(C)$ (range) & $P^{c}$ \\
\hline Total & $62(31 / 50)$ & & $36.0 \pm 0.6(34.6-37.8)$ & \\
\hline Group N & $66.7(12 / 18)$ & NS $(0.84)^{a}$ & $35.8 \pm 0.7(34.6-37.6)$ & NS $(0.09)^{b}$ \\
\hline Group P & $59.4(19 / 32)$ & & $36.1 \pm 0.6(35.0-37.8)$ & \\
\hline \multicolumn{2}{|c|}{ Correct heat loss prevention measures $(n=31)$} & & $36.1 \pm 0.7(35.0-37.8)$ & NS $(0.60)^{b}$ \\
\hline \multicolumn{2}{|c|}{ Incorrect heat loss prevention measures $(n=19)$} & & $36.0 \pm 0.6(34.6-36.9)$ & \\
\hline
\end{tabular}

${ }^{\mathrm{a} C h i-s q u a r e}$

${ }^{\mathrm{b}}$ Paired T-test

'Indicates significance at the $P<0.05$ level. NS non-significant, $P O$ Points Obtained, TPP Total Possible Points, Group N Staff Neonatologists, Group $P$ Pediatricians On-call

\section{Stimulating breathing}

One baby was stimulated when unnecessary, and $32 \%$ $(16 / 50)$ who needed stimulation did not receive it, particularly those in worse condition. One baby had his face rubbed.

\section{Administration of PPV}

One patient was intubated without previous PPV. We observed the following errors: undue delay in starting PPV (at 56, 60 and $69 \mathrm{~s}$ ) in 10.3\% of cases (3/29), use of a self-inflating bag instead of a ventilator in $6.9 \%$ of patients $(2 / 29)$, ventilation without previous suctioning when airway was obstructed in $6.9 \%(2 / 29)$, lack of ventilation between intubation attempts in $3.4 \%(1 / 29)$, and face mask leak in $3.4 \%(1 / 29)$. We did not use a respiratory function monitor, so we could not objectively document leaks; however, in one patient, the lack of a mask seal was obvious. In some patients, more than one mistake occurred.

\section{Intubation}

All intubations deviated from the algorithm. Two of 16 (12.5\%) patients could not be intubated after several attempts; their indication for intubation was respiratory distress. They were transferred to the Neonatal Intensive Care Unit (NICU) with CPAP and intubated under sedation. The mean number of intubation attempts was 2.2 (range 1-6); success on the first attempt happened in $33.3 \%$ of cases; on second attempt, $38.9 \%$; on third attempt, $16.7 \%$; and $11.1 \%$ needed more than three attempts (5 and 6). We analyzed 40 intubation attempts. Two unplanned extubations after surfactant administration (due to incorrect securing of the tube) required reintubation. In all intubation cases, at least one attempt took longer than recommended (30 s). Mean duration to perform intubation was $58.8 \pm$ $23.4 \mathrm{~s}$ (range 17-128 s). Only 5 of 40 intubations (12.5\%) were achieved within $30 \mathrm{~s}$.

\section{Chest compressions and epinephrine administration}

$\mathrm{CC}$ technique was correct, but it was initiated late. Despite correct intubation and ventilation, one newborn was bradycardic at 3:59 min, and CCs were started at
7:22 min. One patient received epinephrine without previous CCs, and another received epinephrine when CCs were started.

The median (IQR) assigned Apgar scores at 1, 5 and 10 min were 7 (5.7-9), $9(8-10)$ and 10 (8-10). The median (IQR) Apgar scores after reviewing NRs were 7 (59), 9 (6.7-10) and 9 (7.7-10). Agreement at the three time points was acceptable (Kappa coefficient 0.35). Interrater reliability in evaluating Apgar scores was moderate at 1, 5 and 10 min (Cohen's kappa coefficients: $0.57,0.60$ and 0.44 , respectively).

Our resuscitation team obtained a median of 10 points per resuscitation (red line), regardless of the resuscitation score (blue line), which means that resuscitations with a resuscitation score above 10 were poorly done (Fig. 2). Figure 3 shows that the relationship between the resuscitation score and the points obtained was nearly logarithmic $\left(R^{2}=0.7053\right)$, which means that resuscitators scored very few additional points as the resuscitation intensity increased.

\section{Discussion}

All our patients were resuscitated in our dedicated room for resuscitation, which provides a setting similar to that in the NICU. Vento [4, 6] suggested that incorporating an intensive care environment into the DR could enhance survival and reduce the morbidity of extremely low birth weight (BW) infants. Among our study population, we found a high percentage of hypothermia (73.5\%), which led us to make some changes in our resuscitation room to reduce hypothermia: we increased the temperature to $26{ }^{\circ} \mathrm{C}$ by keeping the doors locked and installed a heater next to the resuscitation cot. We use heated, humidified gases for ventilation.

Several authors have proven that performance often deviates from guidelines. Our study is the first report on adherence to the neonatal resuscitation algorithm for very preterm infants in a tertiary care center in Spain.

Carbine was the first to use video recording to evaluate NR [16]. We based our study on his publication and adopted his scoring system. Carbine found deviations in $54 \%$ of NRs. We evaluated more aspects and may have detected more errors (84\%). We believe 


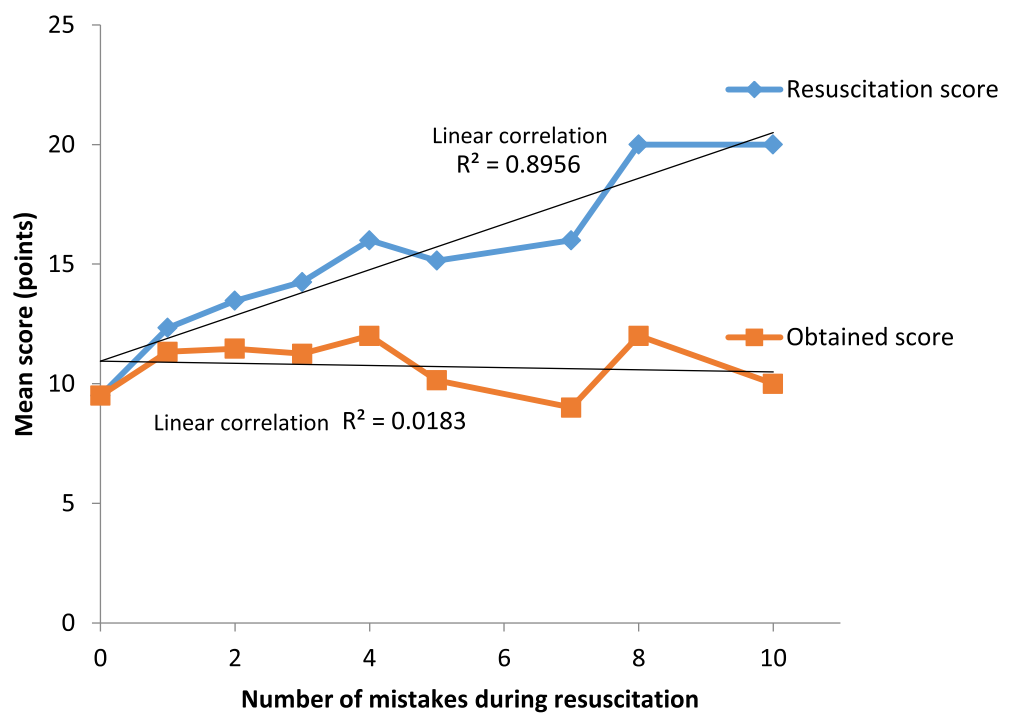

Fig. 2 Correlation between the number of errors during resuscitation and the mean obtained resuscitation score (red line) and the maximum resuscitation score (blue line). The difference between the blue and red lines was the average of virtually lost points

that our resuscitation score was higher: $22 \%$ of Carbine's patients only required stimulation (whereas $64 \%$ of ours needed stimulation); $80 \%$ required stimulation and oxygen, and only $7 \%$ needed PPV (vs our $80 \%$ respiratory support and $32 \%$ intubation). Carbine reported errors in the mask ventilation rate. We considered the use of a self-inflating bag an error, as we used an automatic ventilator. Consequently, we did not find this error. Only 28.6\% of Carbine's cases involving PPV had no deviations, which is worse than our $72.7 \%$ rate of proper ventilation. Among Carbine's infants, $58.3 \%$ were intubated on the first attempt (vs our $33.3 \%$ ), and only $33.3 \%$ (vs our $87.5 \%$ ) were intubated within the established time limit. Like Carbine,

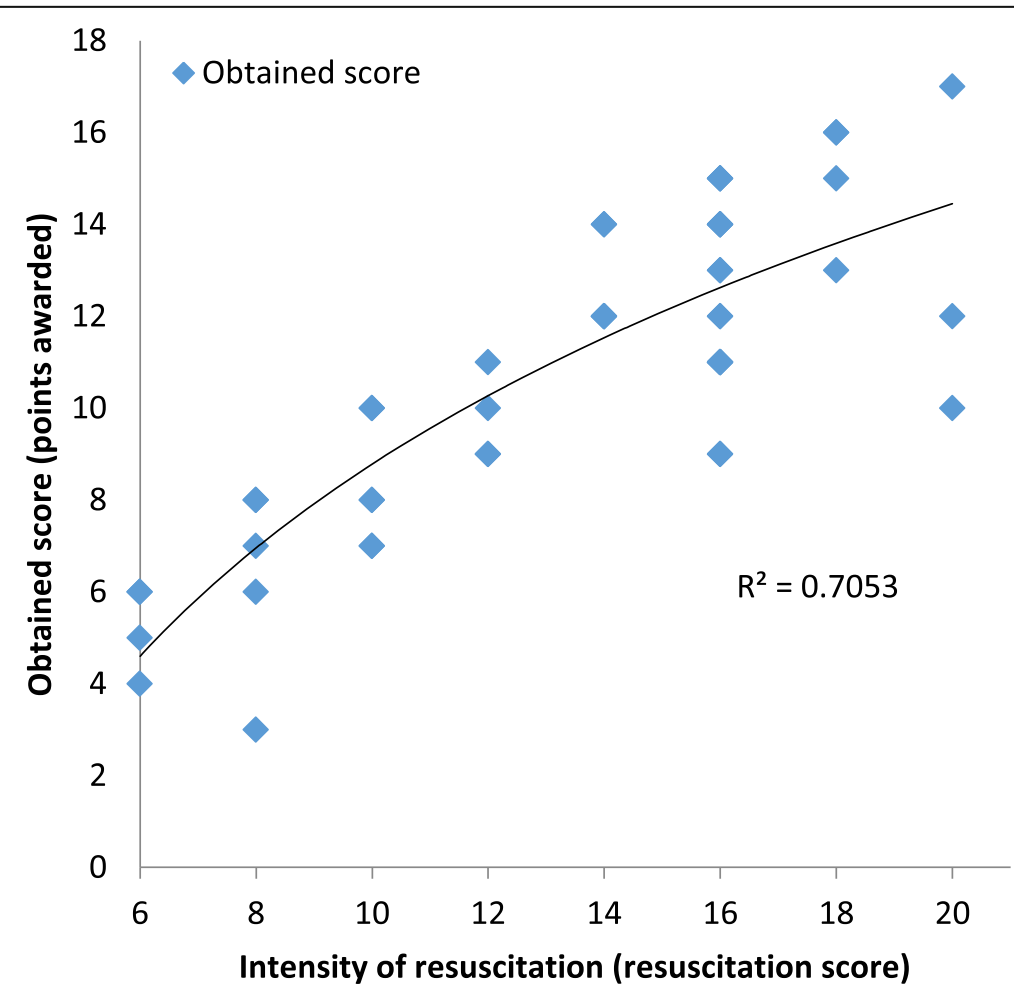

Fig. 3 Relationship between intensity of resuscitation and obtained score 
we observed that perfect resuscitations were more likely for less intense interventions. None of our patients who required intubation received a perfect resuscitation.

Similar to Dekker [17], we observed that stimulation was often indicated but not performed, and when it was applied, it was most often indicated. Dekker's infants who received no stimulation required intubation more often (18 vs $7 \%$ ); in our case, $62.5 \%$ of intubated infants had not been stimulated and $25 \%$ of stimulated infants did not require intubation. However, $18.7 \%$ of infants (6/ 32) who were stimulated were also intubated afterward.

By using video recording at a Nepalese tertiary hospital, Lindbäck [10] identified deviation from guidelines in over $50 \%$ of resuscitations. Most errors concerned the use of bag-and-mask ventilation (which we did not evaluate, as ventilating with a bag and mask was an error in our study), suction and excessive use of oxygen. Their results seem more favorable than ours. However, Lindbäck did not focus on preterm infants.

Gelbart [8] reported that the demanding technical skills scored higher than the more basic steps of resuscitation because technique is taught, whereas clinical assessment, communication skills and teamwork need practice. $\mathrm{He}$ found that invasive ventilation and surfactant administration were best performed, with median scores of $100 \%$, whereas the performance of preparation and initial steps (69\%) and assessment and communication of heart rate (75\%) was worse. In our patients, most errors took place during the initial steps as well, whereas administration of CPAP, PPV and surfactant were performed better. Surfactant was administered in $83.3 \%$ of our cases when indicated. Technique was always correct, although two patients who required it did not receive it; the PO was not functioning, and the pediatrician preferred to administer it in the NICU with proper monitoring.

Schilleman [9] used video recording to evaluate compliance with NR guidelines in a population similar to ours, although our patients were in better conditions according to the Apgar scores. Schilleman found that deviations mainly occurred within the first $30 \mathrm{~s}$ because caregivers needed more time to perform the initial steps and mainly involved the way ventilation was given. As such, Schilleman suggested that $1 \mathrm{~min}$ be allowed for the initial evaluation, which is what the current ILCOR guidelines allow.

No intubations were perfectly performed. We analyzed 40 intubation attempts. Success occurred on the first attempt in $33.3 \%$ of cases and on the second attempt in $38.9 \%$; more than three attempts (5 and 6) were required in only $11.1 \%$ of cases. In all intubation cases, at least one attempt took longer than recommended. Only $12.5 \%$ of intubations took place within the allotted $30 \mathrm{~s}$. Other authors have reported similar deficiencies. Lane
[18] reported a mean duration for successful attempts of $27.3 \mathrm{~s} ; 30 \%$ infants were intubated on the first attempt, $30 \%$ on the second, $20 \%$ on the third, and $20 \%$ required more than three. Success was higher for $30 \mathrm{~s}$, and no infants decompensated between 20 and 30 s; $20 \%$ of successful attempts took longer than $40 \mathrm{~s}$. Finer and Rich's $[3,15]$ overall success rate for intubation was $33 \%$ within the allotted $20 \mathrm{~s}$ and $56 \%$ within $30 \mathrm{~s}$. They reported an average of at least three attempts to successfully intubate infants $<1000$ g. Our intubation success rate was higher than that reported by Finer and Rich. We needed, on average, 2.2 attempts to intubate infants $<1000 \mathrm{~g}$ (range $1-5)$, but unfortunately, it took longer (median (SD) $58.1 \mathrm{~s}$ (23.4), range 17-128 s). O'Donnell [19] analyzed intubation attempts in 31 infants (mean GA 28 weeks and BW $1227 \mathrm{~g}$ ). Intubation attempts were often unsuccessful and successful attempts often took more than $30 \mathrm{~s}$ (17\% were successful within $20 \mathrm{~s}$, $20 \%$ between 20 and $29 \mathrm{~s}$, and $25 \%>30 \mathrm{~s}$ ). Konstantelos [7] needed a median of 2 attempts, and 47 (25-60) s for intubation, and only $11 \%$ were successful within the allotted time. Wozniak [20] analyzed intubation attempts in preterm infants (795 g median BW, 25 weeks' GA) and reported a mean duration of $35 \mathrm{~s}$ and 2 attempts. Like Konstantelos [21], we believe that the lack of medication for intubation and surfactant administration are the reasons for the longer time needed for intubation. Because health care providers often underestimate the passage of time during NR, it is difficult to realize when the allotted time has passed. The American Academy of Pediatrics NRP used to allow $20 \mathrm{~s}$ for intubation, but since several studies reported that it often took longer [3, 16, 18, 19, 21] and that infants did not decompensate between 20 and $30 \mathrm{~s}$, the current limit is $30 \mathrm{~s}$ [20].

As Fig. 2 shows, resuscitators obtained, on average, 10 points per patient regardless of the intensity of resuscitation, which means that caregivers did not score more points in more complex resuscitations. There are two reasons for the constant red line: a) some initial, common mistakes in heat loss prevention, suctioning and a postductal PO probe placement prevented most mild NRs (mean resuscitation score of 13 points) from scoring higher, and $\mathrm{b}$ ) the points corresponding to almost all complex domains (intubation, chest compressions or epinephrine administration) were lost. The consequence is the flat line in the relationship between mistakes and the obtained score. However, the more mistakes that occur in a NR, the higher the resuscitation score (blue line, $R^{2}=0.895$ ), meaning that complex domains (the area above the red line) are lost in terms of obtained points. Not surprisingly, the relationship between the resuscitation score and the obtained score (Fig. 3) followed a strong logarithmic pattern $\left(R^{2}=0.705\right)$. This finding means that although more points are possible, the 
resuscitator team would gain little benefit from those complex domains. More emphasis must be placed on the initial steps, which are common to most NRs, and especially on training for complex skills such as intubation.

This study has some limitations. Its purpose was to evaluate adherence to NR guidelines. For this reason, all mistakes counted equally, although it is obvious that not all the deviations are equally serious: some are mild and nontranscendental (for example, duration of oral suctioning) whereas others are potentially harmful (like timing and route of epinephrine administration). The same mistake could have consequences or not, depending on the patient. For example, placing a postductal PO probe in a patient who does not receive oxygen or ventilatory support has no impact on the maneuvers performed but may lead to hyperoxia in an intubated neonate. Only $16 \%$ of our resuscitations perfectly followed the algorithm, but the number of mistakes per resuscitation was low, and global adherence to the algorithm was $80.9 \%$. We acknowledge that the value of global adherence in itself has little meaning without the proper analysis of the main and more critical errors. Another limitation of our study is the lack of feedback of our findings to the resuscitation team. We designed the study to assess adherence to the algorithm and find the most common errors. In the pilot study, we did not consider an active intervention with the resuscitation team. Sharing our findings with them would probably improve performance. In most cases, the resuscitation team consisted of two neonatologists or two pediatricians on-call. All of them are trained in neonatal resuscitation, although their expertise varies from more than 30 years to only a few months after completing a residency. However, $38 \%$ of our patients were twins, which may worsen performance, as in some cases, there was only one caregiver per patient [22]. All our medical staff was aware of this study when it started, and we periodically reminded them about it. All the neonatologists and pediatricians who work at our hospital participated in this study. The medical staff turned the video camera on, automatically consenting to be recorded, when they were called to the DR. Recording usually began minutes before the neonate was born but sometimes began when the newborn arrived at the resuscitation room.

Similar to many other previous studies, our study demonstrated that deviations from the algorithm exist. Many of the errors have to do with timing: some maneuvers take longer than allotted, and personnel are not aware of this [23].

We compared performance of staff neonatologists with pediatricians on-call. We thought that the neonatologists would perform better since they work with only newborns and are subspecialized in neonatology, whereas after-hour on-call pediatricians who cover this shift often do not work with only newborns. We observed no differences between these two groups, which means that we have a good team of pediatricians who perform as well as neonatologists. This is a positive aspect to consider. Although global adherence to the algorithm was high, mistakes were common despite our staff's training.

In line with other authors $[8,22-25]$, we found a discrepancy in Apgar scores, particularly when the Apgar was not $9 / 10 / 10$, and the staff attending the delivery commonly overestimated the score. It is easy to score $9 /$ $10 / 10$ if no resuscitation is necessary, whereas it is difficult to remember the patient's situation at 5 and $10 \mathrm{~min}$ when resuscitation is required. Video recording scores tended to be lower than scores given by neonatologists (47.1\% at $1 \mathrm{~min}, 73.3 \%$ at $5,88.9 \%$ at 10$)$. Gelbart [8] also found overestimation of Apgar scores by a median value of 2 points at 1 and $5 \mathrm{~min}$. As other authors suggest, we believe that memories of a stressful past event can be inaccurate, and Apgar scores are usually calculated afterward [24].

Finally, we are aware that our study sample was small. We aimed to analyze 50 resuscitations due to the difficulty in obtaining written consent before resuscitation started. Nonetheless, we managed to record one-third of our potential cases, which is a significant sample. The ILCOR guidelines have changed twice since we conducted this study, and some actions that we considered mistakes would now be correct, for example, supporting transition rather than keeping timing strict or not suctioning routinely. While it is true that our data are old, and a few aspects are outdated, our aim was to assess our performance in terms of adherence to the algorithm, that is, if our physicians performed according to the written rules, not the appropriateness of the algorithm. Our results would probably be similar today. Even though only one person reviewed the recordings, the camera was in a good position, and the scoring system was clear, so this bias is likely minimal. There was no feedback given to the resuscitation team during the study period, but our findings could serve as both a starting point for further studies and a teaching tool. As far as we know, there are no similar studies published in Spain to date.

\section{Conclusions}

Resuscitation of very preterm newborns often deviates from guidelines. Perfectly performed resuscitations are infrequent, although global adherence to the algorithm is high. Resuscitations led by pediatricians on-call and neonatologists are performed equally correct. Intubation training may improve complex resuscitations the most. 


\section{Abbreviations}

bpm: Beats Per Minute; BW: Birth Weight; C: Celsius; CC: Chest Compressions; CPAP: Continuous Positive Airway Pressure; DR: Delivery Room; GA: Gestational Age; ILCOR: International Liaison Committee on Resuscitation; min: Minute; NICU: Neonatal Intensive Care Unit; NR: Neonatal Resuscitation; NRP: Neonatal Resuscitation Program; PO: Pulse-Oximeter; PPV: Positive Pressure Ventilation; s: Second; SD: Standard Deviation; Temp: Temperature

\section{Acknowledgements}

We would like to thank the medical and nursing NICU staff for participating and taking ownership during the realization of this project. We thank all the neonatologists and pediatricians on-call for supporting this study.

\section{Availability of data and materials}

The datasets used and analyzed during this study are available from the corresponding author on reasonable request.

\section{Authors' contributions}

SM conceptualized and designed the study, carried out the initial analyses, drafted the initial manuscript and approved the final manuscript as submitted. FB helped to conceptualize and design the study, reviewed and revised the manuscript, and approved the final manuscript as submitted. JF helped to design the study, helped to carry out the statistical analyses, reviewed and revised the manuscript, and approved the final manuscript as submitted. MI-R helped to carry out the initial analyses, reviewed and revised the manuscript, and approved the final manuscript as submitted. MT helped to conceptualize and design the study, helped to develop the neonatal resuscitation algorithm for very preterm infants (2007), reviewed and revised the manuscript, and approved the final manuscript as submitted. MI-S helped to conceptualize and design the study, helped to develop the neonatal resuscitation algorithm for very preterm infants (2007), reviewed and revised the manuscript, and approved the final manuscript as submitted.

\section{Ethics approval and consent to participate}

The Ethics Committee of Hospital Clínic de Barcelona approved this project. We obtained written parental informed consent before recording the infants' resuscitations.

\section{Consent for publication}

Not applicable.

\section{Competing interests}

The authors have no financial relationships relevant to this article to disclose. I declare that I have no competing interests.

\section{Publisher's Note}

Springer Nature remains neutral with regard to jurisdictional claims in published maps and institutional affiliations.

\section{Author details}

'Neonatology Service, Hospital Clínic, seu Maternitat, ICGON (Institut Clínic de Ginecologia, Obstetrícia i Neonatologia), Barcelona University, Sabino de Arana, 1, 08028 Barcelona, Spain. ${ }^{2}$ Neonatology Service, Hospital Sant Joan de Déu, BCNatal (Centre de Medicina Maternofetal i Neonatal de Barcelona, Hospital Sant Joan de Déu, Hospital Clínic), Barcelona University, Passeig de Sant Joan de Déu, 2, 08950 Esplugues de Llobregat, Barcelona, Spain.

Received: 6 June 2018 Accepted: 18 September 2018 Published online: 09 October 2018

\section{References}

1. Perlman JM, Wyllie J, Kattwinkel J, Wyckoff MH, Aziz K, Guinsburg R, et al. Part 7: Neonatal Resuscitation: 2015 International Consensus on Cardiopulmonary Resuscitation and Emergency Cardiovascular Care Science With Treatment Recommendations. Pediatrics. 2015. https://doi.org/10.1542/ peds.2015-3373D.

2. https://data.unicef.org/topic/child-survival/neonatal-mortality/ (accessed 2017 July 25).

3. Finer $N$, Rich $W$. Neonatal resuscitation for the preterm infant: evidence versus practice. J Perinatol. 2010. https://doi.org/10.1038/jp.2010.115.
4. Vento $M$, Cheung PY, Aguar M. The first golden minutes of the extremelylow-gestational-age neonate: a gentle approach. Neonatology. 2009. https:// doi.org/10.1159/000178770.

5. Izquierdo-Renau M, Gómez-Robles C, Pino-Vázquez A. Lección 12. El recién nacido muy prematuro (<32 semanas). In: Sociedad Española de Neonatología. Manual de Reanimación Neonatal. 4th edition. Editorial Ergon. Madrid 2017. Pages 167-180. ISBN: 9788416732494 . Spanish.

6. Vento M, Aguar M, Leone TA, Finer NN, Gimeno A, Rich W, et al. Using intensive care technology in the delivery room: a new concept for the resuscitation of extremely preterm neonates. Pediatrics. 2008. https://doi. org/10.1542/peds.2008-1422.

7. Konstantelos D, Ifflaender S, Dinger J, Rüdiger M. Suctioning habits in the delivery room and the influence on postnatal adaptation - a video analysis. J Perinat Med. 2015. https://doi.org/10.1515/jpm-2014-0188.

8. Gelbart B, Hiscock R, Barfield C. Assessment of neonatal resuscitation performance using video recording in a perinatal centre. J Paediatr Child Health. 2010. https://doi.org/10.1111/j.1440-1754.2010.01747.x.

9. Schilleman K, Siew ML, Lopriore E, Morley CJ, Walther FJ, Te Pas AB. Auditing resuscitation of preterm infants at birth by recording video and physiological parameters. Resuscitation. 2012. https://doi.org/10.1016/j. resuscitation.2012.01.036.

10. Lindbäck C, KC A, Wrammert J, Vitrakoti R, Ewald U, Målqvist M. Poor adherence to neonatal resuscitation guidelines exposed; an observational study using camera surveillance at a tertiary hospital in Nepal. BMC Pediatr. 2014. https://doi.org/10.1186/1471-2431-14-233.

11. Finer NN, Rich W. Neonatal resuscitation: toward improved performance. Resuscitation. 2002;53(1):47-51.

12. Murphy MC, O'Donnell CPF, McCarthy LK. Attittudes of staff members towards video recording in the delivery room. Arch Dis Child Fetal Neonatal Ed. 2018. https://doi.org/10.1136/archdischild-2017-313789.

13. den Boer MC, Houtlosser M, van Zanten HA, Foglia EE, Engberts DP, Te Pas AB. Ethical dilemmas of recording and reviewing neonatal resuscitation. Arch Dis Child Fetal Neonatal Ed. 2018. https://doi.org/10.1136/archdischild-2017-314191.

14. Van Vonderen JJ, van Zanten HA, Schilleman K, Hooper SB, Kitchen MJ, Witlox RS, et al. Cardiorespiratory Monitoring during Neonatal Resuscitation for Direct Feedback and Audit. Front Pediatr. 2016. https://doi.org/10.3389/ fped.2016.00038.

15. Rich WD, Leone T, Finer NN. Delivery room intervention: improving the outcome. Clin Perinatol. 2010. https://doi.org/10.1016/j.clp.2010.01.011.

16. Carbine DN, Finer NN, Knodel E, Rich W. Video recording as a means of evaluating neonatal resuscitation performance. Pediatrics. 2000;106:654-8.

17. Dekker J, Martherus T, Cramer SJE, van Zanten HA, Hooper SB, Te Pas AB. Tactile stimulation to stimulate spontaneous breathing during stabilization of preterm infants at birth: a retrospective analysis. Front Pediatr. 2017;5:61. https://doi.org/10.3389/fped.2017.00061

18. Lane B, Finer N, Rich W. Duration of intubation attempts during neonatal resuscitation. J Pediatr. 2004. https://doi.org/10.1016/j.jpeds.2004.03.003.

19. O'Donnell CP, Kamlin CO, Davis PG, Morley CJ. Endotracheal intubation attempts during neonatal resuscitation: success rates, duration, and adverse effects. Pediatrics. 2006. https://doi.org/10.1542/peds.2005-0901.

20. Wozniak M, Arnell K, Brown M, Gonzales S, Lazarus D, Rich W, et al. The 30 second rule: the effects of prolonged intubation attempts on oxygen saturation and heart rate in preterm infants in the delivery room. Minerva Pediatr. 2018. https://doi.org/10.23736/S0026-4946.16.04469-8.

21. Konstantelos D, Dinger J, Ifflaender S, Rüdiger M. Analyzing video recorded support of postnatal transition in preterm infants following a c-section. BMC Pregnancy Childbirth. 2016. https://doi.org/10.1186/s12884-016-1045-2.

22. Layouni I, Danan C, Durrmeyer X, Dassieu G, Azcona B, Decobert F. Video recording of newborn resuscitation in the delivery room: technique and advantages. Arch Pediatr 2011; doi: https://doi.org/10.1016/S0929693X(11)71094-6. French.

23. Trevisanuto D, De Bernardo G, Res G, Sordino D, Doglioni N, Winer G, et al. Time Perception during Neonatal Resuscitation. J Pediatr. 2016. https://doi. org/10.1016/j.jpeds.2016.07.003.

24. McCarthy LK, Morley CJ, Davis PG, Kamlin CO, O'Donnell CP. Timing of interventions in the delivery room: does reality compare with neonatal resuscitation guidelines? J Pediatr. 2013. https://doi.org/10.1016/j.jpeds.2013.06.007.

25. Schilleman K, Witlox RS, van Vonderen JJ, Roegholt E, Walther FJ, te Pas AB. Auditing documentation on delivery room management using video and physiological recordings. Arch Dis Child Fetal Neonatal Ed. 2014. https://doi. org/10.1136/archdischild-2014-306261. 